\title{
Management of obsessive-compulsive disorder with fluvoxamine extended release
}

This article was published in the following Dove Press journal:

Neuropsychiatric Disease and Treatment

22 May 2009

Number of times this article has been viewed

Lídia Ordacgi'

Mauro V Mendlowicz ${ }^{2}$

Leonardo F Fontenelle'

'Anxiety and Depression Research Program, Institute of Psychiatry, Universidade Federal do Rio de Janeiro (IPUB/UFRJ), Rio de Janeiro, Brazil; 'Department of Psychiatry and Mental Health, Universidade Federal Fluminense (MSM-UFF), Niterói, Brazil
Correspondence: Leonardo F Fontenelle Rua Visconde de Pirajá 547, sala 719, Ipanema Rio de Janeiro, RJ 224I 0-003, Brazil $\mathrm{Tel} / \mathrm{Fax}+552122394919$

Email Ifontenelle@gmail.com

\begin{abstract}
The pharmacodynamic properties of fluvoxamine maleate include the modulation of different populations of serotonergic, dopaminergic, and sigma receptors and/or transporters, a complex pattern of activity that may account for its efficacy in the treatment of obsessivecompulsive disorder (OCD). Nevertheless, its pharmacokinetic profile and its pattern of side effects may hinder a rapid dose escalation, a therapeutic strategy that might be utterly desirable in patients with OCD. In preclinical studies, the maximum plasma concentration and bioavailability of an extended-release (CR) formulation of fluvoxamine were, respectively, $38 \%$ and $16 \%$ lower than those of the standard (ie, non-CR) formulation. Recently, the US Food and Drug Administration approved the fluvoxamine CR formulation for the treatment of OCD in adults. This approval was based on the results of a double-blind, placebo-controlled study with 253 OCD patients in which fluvoxamine CR showed a consistently earlier onset of therapeutic effects than other selective serotonin reuptake inhibitors, as reported in previous studies. The use of the CR formulation of fluvoxamine allowed a particularly aggressive dosing strategy at the beginning of the titration phase, ie, treatment could be started with a single dose of fluvoxamine CR $100 \mathrm{mg}$ at bedtime, while keeping the occurrence of side effects and the rate of compliance at levels comparable to those reported for the use of immediate-release fluvoxamine.
\end{abstract}

Keywords: obsessive-compulsive disorder, fluvoxamine, fluvoxamine extended release

\section{Introduction}

Fluvoxamine maleate is a selective serotonin reuptake inhibitor (SRI) that belongs to a distinct chemical series: the 2-aminoethyl oxime ethers of aralkylketones. ${ }^{1}$ Fluvoxamine maleate is structurally unrelated to other selective SRIs and to clomipramine. It is chemically designated as 5-methoxy-4'-(trifluoromethyl) valerophenone-(E)-O(2-minoethyl) oxime maleate (1:1). It does not have an asymmetric carbon in its structure and therefore does not exist as optical isomers. For this reason, the potentially confounding issue of stereoisomerism does not arise with fluvoxamine. ${ }^{2}$

Clinical trials with immediate-release (IR) formulations of fluvoxamine in depression started in the 1970s and marketing approval was first obtained in Switzerland in 1983. Fluvoxamine IR started to be systematically tested in the treatment of obsessive-compulsive disorder (OCD) in the US in the late $1980 \mathrm{~s}^{3}$ and gained US Food and Drug Administration (FDA) approval by the end of 1994. Recently, an extendedrelease (CR, controlled-release) formulation of fluvoxamine was approved by FDA for the treatment of social anxiety disorder (SAD) and OCD in adults. Fluvoxamine CR incorporates Spheroidal Oral Drug Absorption System [SODAS(R)] technology, 
a method designed to minimize peak-to-trough plasma level fluctuations over a 24-hour period.

In this report, we aimed to critically review the phamacodynamics, pharmacokinetics, efficacy, and tolerability of fluvoxamine in general, and of its CR formulation in particular, in the context of the treatment of patients with OCD.

\section{Pharmacodynamics of fluvoxamine}

The mechanism of action of fluvoxamine maleate in OCD is thought to involve serotonin reuptake inhibition in brain neurons. Fluvoxamine was shown to be a potent inhibitor of the serotonin reuptake transporter in preclinical studies, both in vitro and in vivo. Although there is some variability across studies, fluvoxamine appears to be a more potent inhibitor of in vitro serotonin reuptake than fluoxetine, but less powerful than paroxetine, sertraline, citalopram, and escitalopram. ${ }^{1,4}$ Among the SRIs, fluvoxamine is one of the weakest inhibitors of norepinephrine and dopamine reuptake. ${ }^{1}$ In in vitro studies, fluvoxamine maleate had no significant affinity for histaminergic, adrenergic, or muscarinic receptors, which are responsible for the various sedative, cardiovascular, and anticholinergic side effects commonly observed during treatment with many psychotropic drugs. We will now discuss the putative pathways through which fluvoxamine leads to symptom improvement of patients with OCD, including the modulation of serotonergic, dopaminergic, and sigma transporters or receptors.

\section{Serotonergic receptors}

Only high doses of potent SRIs, such as clomipramine, fluvoxamine, fluoxetine, sertraline, paroxetine, citalopram, and escitalopram, are consistently effective in the treatment of OCD, particularly when administered for at least 12 weeks. ${ }^{5}$ Furthermore, when patients with OCD who were successfully treated with clomipramine were switched in a double-blind fashion to desipramine, a selective noradrenergic reuptake inhibitor, they frequently relapsed. ${ }^{6}$ In the same vein, the adding of desipramine to the therapeutic scheme of OCD patients did not lead to any additional improvement. ${ }^{7}$ It has thus been argued that the anti-OCD effect of the SRIs results largely from the inhibition of the serotonin reuptake process, rather than from a non-specific antidepressant mechanism. ${ }^{8,9}$ Indeed, several drug trials and meta-analytic studies have shown that the anti-OCD effect of SRIs is independent from the presence of depression. ${ }^{10,11}$

Recently, El Mansari and Blier ${ }^{12}$ argued that the delayed therapeutic response to high doses of SRI in OCD is congruent with the time course of the desensitization of terminal
$5-\mathrm{HT}_{1 \mathrm{D}}$ receptors and of the increase in serotonin release in orbitofrontal cortex (OFC). They further hypothesized that enhanced serotonin release in the OFC results both in a decrease of the sensitivity of $5-\mathrm{HT}_{1 \mathrm{~A}}$ receptors and in an activation of normosensitive postsynaptic 5- $\mathrm{HT}_{2}$-like receptors, a biological cascade that could underlie the therapeutic actions of SRIs in OCD. This model is further supported by the serendipitous beneficial effect in OCD of some hallucinogens with $5-\mathrm{HT}_{2}$ agonistic properties. Further, while low doses of the $5-\mathrm{HT}_{2}$ antagonist risperidone has been shown to exert a positive therapeutic effect in SRI-resistant OCD patients, high doses of clozapine or risperidone cause an exacerbation of OCD symptoms, probably due to the antagonism of $5-\mathrm{HT}_{2}$ receptors in OFC. ${ }^{12}$ Accordingly, Moresco et $\mathrm{al}^{13}$ found that fluvoxamine increased the in vivo binding of fluoro-ethyl-spiperone, a high affinity $5-\mathrm{HT}_{2}$ serotonin receptor antagonist, in the frontal and occipital cortex of nine patients with major depressive disorder.

Molecular neuroimaging studies suggest that even small doses of fluvoxamine may exert significant serotonergic effects. For example, Suhara et al ${ }^{14}$ observed that a dosage as low as $50 \mathrm{mg}$ /day of fluvoxamine maleate, either administered as a single dose or over a 6-month period, was associated with approximately $80 \%$ of occupancy of the serotonin transporters. In a prospective study, Takano et al ${ }^{15}$ performed positron emission tomography scans before and 5 hours, 26 hours, and 53 hours after the administration of $50 \mathrm{mg}$ of fluvoxamine to 6 healthy male volunteers. Mean serotonin transporter occupancies were $72.9 \% \pm 4.9 \%$ at 5 hours, $50.3 \% \pm 11.0 \%$ at 26 hours, and $24.7 \% \pm 15.3 \%$ at 53 hours. Taken together, these findings suggest that while in low doses fluvoxamine occupies a significant percentage of serotonin transporters, in doses higher than $50 \mathrm{mg} /$ day, like the ones that are usually required for the treatment of OCD, it likely recruits also other neurotransmitter systems or receptors.

\section{Dopaminergic receptors}

It is likely that different SRIs (including fluvoxamine) and dopaminergic antagonists have similar effects on certain neurobiological systems. In a pharmacological fMRI study conducted by Takahashi et $\mathrm{al}^{16}$ both fluvoxamine and sultopride, a D2 receptor antagonist, attenuated the activity in the amygdala of healthy volunteers during exposure to unpleasant pictures, although the two treatments had slightly different modulatory effects on other components of the neural circuit of emotional processing. Unlike sutopride, fluvoxamine reduced activation in the orbito-frontal 
cortex (OFC), basal ganglia, and insula and induced greater activation in the temporal and parietal cortex.

Indeed, some authors have debated whether fluvoxamine and other SRIs exert their antiobsessional effects solely through an increase in the levels of serotonin or by an ultimate regulation of dopaminergic receptors. ${ }^{17}$ Accordingly, in a PET study, Moresco et $\mathrm{al}^{18}$ found that fluvoxamine treatment increased the availability of dopaminergic type 2 (D2) receptors in the dorsal and ventral striatum of patients with OCD who responded to treatment. Of note, after a 12-week treatment, responders had mean binding potential values closer to those of normal volunteers, while the non-responder patients did not show increases in binding potential values in the dorsal part of the basal ganglia. Therefore, there is some evidence suggesting that fluvoxamine is able to modify the dopaminergic system, in general, and the availability of striatal dopamine D2 receptors, in particular, in patients with OCD. In light of these results, the increase in the availability of receptors may be consequent to the reduction of dopamine concentration induced by fluvoxamine and other SRIs. ${ }^{19}$

\section{Sigma receptors}

Sigma receptors are a unique set of proteins $\left(\sigma_{1}\right.$ and $\left.\sigma_{2}\right)$ located in different neurons throughout the brain, particularly within their endoplasmic reticulum (ER). ${ }^{20}$ While the functions of $\sigma_{2}$ receptors are not well understood, the occupancy of $\sigma_{1}$ receptors by its agonists causes translocation of this receptor from the ER to peripheral areas (membranes) of neurons, where $\sigma_{1}$ regulates ion channels and the release of glutamate, dopamine, serotonin, norepinephrine, and acetylcoline, among other neurotransmitters. ${ }^{21}$

In animal studies, fluvoxamine, best known for its serotonin-reuptake inhibition, exhibits the strongest affinity and highest level of occupancy of $\sigma_{1}$ receptors among all anti-OCD agents. ${ }^{22}$ Indeed, in a study by Ishikawa et $\mathrm{al}^{23}$ 15 healthy individuals were submitted to two PET scans using the selective $\sigma_{1}$ receptor ligand [(11) C] SA4503 before and after a single dose of either fluvoxamine $(50,100,150$, or $200 \mathrm{mg}$ ) or paroxetine $(20 \mathrm{mg})$. While fluvoxamine bound to $\sigma_{1}$ receptors in all brain regions in a dose-dependent manner, paroxetine did not, thus suggesting that, at therapeutic doses, $\sigma_{1}$ receptors may be specifically involved in the mechanisms of action of fluvoxamine.

Further, Egashira et $\mathrm{al}^{24}$ found that fluvoxamine inhibits OCD-like behaviors in animal models ("marbleburying behavior"). In this experimental paradigm, burying begins as an appropriate, investigative activity but, after frustrated investigation of a non-reactive stimulus object (ie, the marble), it persists as a compulsive stereotypy. This observation is in line with the view that compulsive behaviors result from one's inability to achieve a sense of task completion. ${ }^{25}$ In the study by Egashira et $\mathrm{al}^{24}$ fluvoxamine inhibited burying behavior not only through the inhibition of the serotonin transporter, but also by means of the activation of $\sigma_{1}$ receptors, while paroxetine, another SRI, inhibited this behavior mainly through the inhibition of the serotonin transporter. In fact, other selective $\sigma_{1}$ receptors agonists, like the neurosteroids, were already found to inhibit other animal models of OCD. ${ }^{20}$

\section{Pharmacokinetics of fluvoxamine}

Fluvoxamine exhibits significant particularities in its pharmacokinetics, including the lack of pharmacological activity of its metabolites, a low degree of binding to plasma proteins, and a high affinity for various cytochrome P450 (CYP) enzymes. $^{26}$

After oral administration, fluvoxamine is nearly completely absorbed from the gastrointestinal tract, and the extent of the absorption is unaffected by the presence of food. ${ }^{2,27}$ In a single-dose crossover study involving 28 healthy subjects, fluvoxamine CR maximum plasma concentration and bioavailability were, respectively, $38 \%$ and $16 \%$ lower than those of the standard (ie, non-CR) formulation. ${ }^{28}$

In a multiple-dose proportionality study, fluvoxamine CR capsules were administered to 20 healthy volunteers with doses ranging from $100 \mathrm{mg} /$ day to $300 \mathrm{mg}$ /day. Steadystate plasma concentrations were achieved within a week. ${ }^{28}$ A study using fluorine-19 magnetic resonance spectroscopy showed that fluvoxamine IR concentrations reached steady state in the brain within approximately 1 month after consistent dosing, which is substantially more rapid than previously observed for fluoxetine. ${ }^{29}$ It has been suggested that fluvoxamine displays nonlinear steady-state pharmacokinetics, ie, disproportionately higher plasma concentrations with increased dosages. ${ }^{2,26,27}$ Since high doses of fluvoxamine are often required during the treatment of $\mathrm{OCD},{ }^{5}$ caution should be exercised when uptitrating its dose in order to avoid reaching toxic levels.

The mean apparent volume of distribution for fluvoxamine is approximately $25 \mathrm{~L} / \mathrm{kg}$, suggesting extensive tissue distribution. ${ }^{28}$ The plasma protein binding of fluvoxamine has been reported to be circa $80 \%,{ }^{27,30}$ the lowest value for any of the selectve SRI. ${ }^{26}$

Fluvoxamine undergoes extensive oxidative metabolism, most probably in the liver. ${ }^{2}$ The drug is metabolized to at least 11 biotransformation products that are recovered in the urine 
after oral administration of radiolabeled fluvoxamine. ${ }^{27} \mathrm{Of}$ the products that have been so far identified, none showed any significant pharmacologic activity. ${ }^{26,27}$ The specific cytochrome P450 (CYP) isoenzymes involved in the metabolism of fluvoxamine are unknown. ${ }^{2,26}$ CYP2D6, which is crucially involved in the metabolism of paroxetine and fluoxetine, appears to play a clinically insignificant role in the metabolism of fluvoxamine. ${ }^{2}$

The drug is excreted in the urine, predominantly as metabolites, with only negligible amounts $(<4 \%)$ of the active parent compound. ${ }^{2}$ Fluvoxamine shows a biphasic pattern of elimination with a mean terminal elimination halflife of 12 to 22 hours after a single oral dose, ${ }^{2,26}$ this half-life is prolonged by $30 \%$ to $50 \%$ at steady state. ${ }^{2}$ After the oral administration of a single $100 \mathrm{mg}$ capsule of fluvoxamine $\mathrm{CR}$, the mean plasma half-life of fluvoxamine in healthy male and female volunteers was 16.3 hours. ${ }^{28}$ Fluvoxamine pharmacokinetics is substantially unaltered by increased age or renal impairment. However, its elimination is prolonged in patients with hepatic cirrhosis. ${ }^{2,27}$ For a comparison between the pharmacokinetics properties of different formulations of fluvoxamine, see Table 1.

In a study using fluorine-19 magnetic resonance spectroscopy (19F MRS), the elimination half-lives of fluvoxamine in brain and plasma were determined to assess their interdependence. ${ }^{31}$ In this study, the mean ratio of fluvoxamine brain elimination half-life to plasma half-life was 2.4 , thus suggesting that fluvoxamine is eliminated from brain at a slower pace than from plasma.

Fluvoxamine inhibits oxidative drug metabolizing enzymes (particularly CYP1A2, and less potently, CYP3A4 and CYP2D6) and has the potential for clinically significant drug interactions. ${ }^{2}$ In the management of OCD, an array of different augmentation strategies may be employed in patients who exhibit only partial response to selective SRIs, including the use of clomipramine or of atypical antipsychotics as an add-on therapy. ${ }^{5}$ Clinicians should take into account the fact that fluvoxamine may lead to increased plasma levels of the augmentation drugs, either by inhibiting the CYP 1 A2 (ie, haloperidol, olanzapine, and clomipramine) or the CYP3A4 (ie, haloperidol, pimozide, risperidone, quetiapine, and clomipramine). Depending on the ability of the prescriber, these interactions may lead to either an increased efficacy or to toxicity. ${ }^{28,32,33}$

\section{Efficacy of fluvoxamine IR in OCD}

The efficacy of fluvoxamine in the management of OCD has been confirmed by a number of randomized, double-blind, controlled studies, making it the first selective SRI to be registered for this clinical indication. ${ }^{34}$ Placebo-controlled studies conducted over 6 to 12 weeks have consistently shown a significantly greater response to fluvoxamine IR (100-300 mg/day) as assessed by the Yale-Brown Obsessive-Compulsive Scale (Y-BOCS), the National Institute of Mental Health Obsessive-Compulsive (NIMH-OC) scale, and the CGI scales. ${ }^{35-38}$ According to a review on the studies of fluvoxamine IR in OCD, no significant correlation between plasma fluvoxamine levels and treatment response was found. ${ }^{1}$ There is some evidence from two early placebo-controlled studies suggesting that fluvoxamine significantly augments the efficacy of behavior therapy. ${ }^{39,40}$

The majority of double-blind, active treatmentcontrolled studies of fluvoxamine have been conducted with clomipramine, another SRI. ${ }^{41-45}$ All these studies found that fluvoxamine and clomipramine were equally effective for the treatment of OCD. Although meta-analytic

Table I Comparison between the pharmacokinetic parameters of IR and CR formulations of fluvoxamine

\begin{tabular}{lll}
\hline & Fluvoxamine IR & Fluvoxamine CR \\
\hline Bioavailability & $6 \mathrm{~h}$ & $15 \mathrm{~h}$ \\
$\mathrm{~T}_{\max }$ & $41.88 \mathrm{ng} / \mathrm{mL}( \pm \mid 8.99)$ & $25.78 \mathrm{ng} / \mathrm{mL}( \pm \mathrm{I5.66)}$ \\
$\mathrm{C}_{\max }$ & $959.33 \mathrm{ng} \times \mathrm{h} / \mathrm{mL}( \pm 520.7 \mathrm{I})$ & $806.3 \mathrm{I} \mathrm{ng} \times \mathrm{h} / \mathrm{mL}( \pm 450.92)$ \\
$\mathrm{AUC}_{(0-\mathrm{inf})}$ & $25 \mathrm{~L} / \mathrm{kg}$ & $25 \mathrm{~L} / \mathrm{kg}$ \\
Volume of distribution $_{\text {Plasma protein-binding }}$ & $80 \%$ & $80 \%$ \\
Metabolism & Deamination and oxidative demethylation & Deamination and oxidative demethylation \\
Plasma half-life & $15.9 \mathrm{~h}$ & $16.3 \mathrm{~h}$ \\
Excretion & Renal & Renal \\
\hline
\end{tabular}

Abbreviations: IR, immediate release; $C R$, extended release; $T_{\max }$, time to maximum plasma concentration; $C_{\text {max }}$, maximum plasma concentration; $A U C{ }_{(0-\text { inf }}$, area under the curve. 
studies suggest that there is a small advantage for clomipramine over fluvoxamine and other selective SRI, they generally confirmed that its lower tolerability, as will be discussed below, makes clomipramine a second-line medication. ${ }^{10,11,46}$

Fluvoxamine is the only selective SRI that has been tested so far against a noradrenaline reuptake inhibitor, desipramine, in the acute treatment of OCD. ${ }^{8}$ Both the rate of response and the change from baseline to endpoint in YBOCS scores were significantly greater with fluvoxamine than with desipramine. Long-term maintenance treatment with fluvoxamine seems to reduce the risk of relapse, and there is some indication that lower dosages may also be effective, although only small scale studies have been conducted to date. ${ }^{47,48}$

Few neuroimaging studies have investigated the presence of predictors of response to fluvoxamine among patients with OCD. Rauch et $\mathrm{al}^{49}$ found that lower regional cerebral blood flow ( $\mathrm{rCBF}$ ) values in $\mathrm{OFC}$ and higher $\mathrm{rCBF}$ values in posterior cingulate cortex predicted better treatment response to fluvoxamine among patients with contamination-related OCD. This same pattern of associations was present regardless of whether the imaging data were acquired during a provoked or neutral state. Conversely, Ho Pian et $\mathrm{al}^{50}$ reported that levels of $\mathrm{rCBF}$ decreased significantly in the left caudate nucleus and in the left and right putamen in both responders and nonresponders to treatment with fluvoxamine. However, only in responders a significant decrease in $\mathrm{rCBF}$ was found in the right thalamus. Taken together, these findings suggest that the pattern of activity of structures from the corticostriato-thalamo-cortical circuit may help predict individuals who will respond to treatment with fluvoxamine, a finding that is consistent with the results obtained in prediction studies with other SRIs.

\section{Efficacy of fluvoxamine CR in OCD}

Patients with OCD often require long-term treatment. However, discontinuation of drug treatment remains a significant hurdle in the management of patients with OCD, leading to relapse in the majority of cases, even when treatment has been administered for more than 2 years. ${ }^{51}$ This is particularly true when drug treatment has not been combined with cognitive-behavioral therapy. ${ }^{52}$ Therefore, not only substantial symptom relief, but also better drug tolerability and a convenient dosing regimen are equally important for increasing treatment compliance of patients with OCD. ${ }^{53}$
Controlled-release formulations of newer antidepressants, including fluvoxamine, could lead to less short-term side effects and facilitate a more rapid titration regimen, an approach that could hasten treatment response in OCD. ${ }^{54}$ In addition, by producing more stable blood levels, such CR formulations would reduce the large swings in plasma levels observed between doses and decrease the frequency of administration required to maintain therapeutic levels. ${ }^{55}$ Recently, a new CR formulation of fluvoxamine maleate, fluvoxamine $\mathrm{CR}$, with peculiar pharmacokinetic features, has been developed, tested, and approved by the FDA for the treatment of adult patients with OCD.

In a multicenter randomized, double blind, 12-week long placebo-controlled study, Hollander et $\mathrm{al}^{53}$ compared the efficacy and safety of a flexible dosing of fluvoxamine CR (100-300 mg/day) to placebo in the treatment of patients with OCD. In this study, a particularly aggressive dosing strategy was adopted at the beginning of the titration phase: subjects who were randomly assigned to receive fluvoxamine CR began with a bedtime dose of $100 \mathrm{mg}$ and were progressively titrated, in weekly increments of $50 \mathrm{mg}$ (if tolerated), to a final bedtime dose ranging from 100 to $300 \mathrm{mg}$ /day over the first 6 weeks of treatment; thereafter, the dose remained constant for the duration of the doubleblind period. The starting dose was twice the dose usually employed in earlier comparable studies of fluvoxamine IR in OCD. Hollander et $\mathrm{l}^{53}$ demonstrated that fluvoxamine CR was significantly superior to placebo in all efficacy measures, including the change from baseline to endpoint in Yale-Brown Obsessive-Compulsive Scale (Y-BOCS) and Clinical Global Impression (CGI)-severity scores, as well as CGI-improvement scores and responder rate at endpoint. Unfortunately, this study did not report any attempt to establish the therapeutic plasma concentration range of fluvoxamine.

The magnitude of the decreases from baseline to endpoint in the Y-BOCS total score (fluvoxamine CR $8.5 \pm 0.7$ [31.7\% change] vs placebo $5.6 \pm 0.7$ [21.2\% change]) and CGI severity score (fluvoxamine CR $2.7 \pm 0.1$ vs placebo $3.2 \pm 0.1$ ) for subjects treated with fluvoxamine CR in this study were similar to those observed in previous studies with fluvoxamine IR, ${ }^{37,38}$ fluoxetine, ${ }^{56}$ paroxetine, ${ }^{57}$ and sertraline. ${ }^{58}$ Also, the rates of remission were significantly higher in the fluvoxamine CR-treated patients than in the placebo group (44 versus $31 \%$ and 18 versus $8 \%$, given Y-BOCS threshold values $<16$ and $<8$, respectively). Of interest, while the differences between fluvoxamine IR and placebo emerged from the 4th to the 10th week of treatment in early 
studies of patients with primary OCD, ${ }^{35-38}$ the differences between fluvoxamine $\mathrm{CR}$ and placebo in Hollander et $\mathrm{al}^{37}$ study achieved statistical significance at the second week of treatment both in the primary efficacy variable (ie,the Y-BOCS total score) and in the secondary efficacy variables (ie, CGI-score and responder rate). In other words, fluvoxamine CR showed a consistent earlier onset of therapeutic effects across different efficacy parameters when compared with the findings of previous studies involving other selective SRI. Unfortunately, however, no discontinuation study of fluvoxamine CR in OCD was conducted so far. Therefore, no information regarding the percentage and speed of relapse is available.

Hollander et $\mathrm{al}^{53}$ proposed several possible explanations for the earlier onset of action of fluvoxamine CR. First, because fluvoxamine CR exhibits less circadian fluctuation in plasma levels (peak to trough concentration), patients may benefit from having drug concentrations that are above the minimally therapeutically effective one during most of the day. Second, because fluvoxamine CR has a lower maximal concentration compared with fluvoxamine after the same dosing, subjects could be started at a higher dosage of fluvoxamine CR but still enjoyed a similar tolerability profile, akin to a pulse loading strategy with clomipramine. ${ }^{59}$ Third, the more rapid dose escalation of fluvoxamine CR compared with conventional fluvoxamine may allow for earlier effects on gene expression, as has been suggested in pulse-loading intravenous treatment studies in OCD. ${ }^{59}$

The earlier response to fluvoxamine CR observed in patients with OCD must be viewed with caution. For example, in the study by Westenberg et $\mathrm{al}^{60}$ who investigated the effectiveness of this formulation in patients with SAD, fluvoxamine CR was titrated in a similar fashion to that adopted in the OCD study ${ }^{53}$ but differed from placebo only after the fourth week of treatment.

In fact, since both disorders were previously found to exhibit similar patterns of response to selective SRIs, we can only speculate about the reasons underlying this apparently inconsistent finding. First, the mean endpoint dose of fluvoxamine CR was $271 \mathrm{mg} /$ day in the OCD study and $209 \mathrm{mg}$ /day in the SAD study. Second, the Liebowitz Social Anxiety Scale, which was the primary efficacy variable in Westenberg et $\mathrm{al}^{59}$ study, may be less sensitive to early changes exhibited by patients with SAD than Y-BOCS is to changes shown by patients with OCD. Finally, there may be some unidentified differences other than the diagnoses between the samples recruited for these studies. One way or another, further controlled studies are needed to elucidate whether the earlier onset of action of fluvoxamine CR in OCD patients is also found in patients with other anxiety or mood disorders.

\section{Tolerability of fluvoxamine CR}

Fluvoxamine IR exhibits antiobsessional properties similar to those of other selective SRIs and clomipramine, but has a somewhat superior tolerability profile than clomipramine, particularly with respect to a lower incidence of anticholinergic effects and reduced cardiotoxic potential. ${ }^{37}$ However, gastrointestinal adverse effects are seen more frequently with fluvoxamine IR than with tricyclic antidepressants. ${ }^{2}$ Indeed, in controlled trials in OCD and depression, the most commonly reported side effects likely to be related to fluvoxamine IR (ie, whose incidence is 5\% or greater and at least twice that for placebo) were nausea ( $40 \%$ in active drug vs $14 \%$ in placebo), somnolence $(22 \%$ in active drug vs $8 \%$ in placebo) and insomnia (21\% in active drug vs $10 \%$ in placebo). ${ }^{61}$

Reduced fluctuations in plasma concentration observed during treatment with fluvoxamine CR may be associated with fewer side effects. The tolerability of fluvoxamine CR has been studied in two controlled trials of social anxiety disorder $(\mathrm{N}=579)^{60,62}$ and one trial of OCD $(\mathrm{N}=124) .{ }^{53}$ In general, adverse event rates were similar in the two data sets. As for fluvoxamine IR, the most commonly observed adverse events associated with the use of fluvoxamine $\mathrm{CR}$ for patients in social anxiety disorder were nausea (315\%-47\% vs $6 \%-15 \%)$, somnolence $(22 \%-31 \%$ vs $7 \%-10 \%)$, insomnia (31\%-32\% vs $11 \%-15 \%)$, and asthenia (28\% vs $13 \%) .{ }^{60,62}$ In both studies, no weight gain was observed for either treatment group, and at end point there were no differences between treatments on overall sexual function, as measured by the Arizona Sexual Experience Scale. ${ }^{60,62}$ By the same token, the most commonly observed adverse events associated with the use of fluvoxamine CR and likely to be drug-related (incidence of $5 \%$ or greater and at least twice that for placebo) for patients with OCD were insomnia (35\% vs 20\%), nausea (34\% vs 13\%), somnolence ( $27 \%$ vs $11 \%$ ), asthenia ( $25 \%$ vs $8 \%$ ), diarrhea (18\% vs $8 \%$ ), and anorexia (13\% vs $5 \%) .{ }^{53}$

As seen in the above-mentioned studies, even though the fluvoxamine CR starting dose was higher (100 mg/day) and taken once daily, the profile of side effects associated with fluvoxamine CR remained roughly the same of those seen in early fluvoxamine IR studies, in which lower, divided doses were employed. ${ }^{37,38}$ In the fluvoxamine CR study in OCD patients, while a higher proportion of subjects in 
the active treatment group (19\%) discontinued treatment due to adverse events (as compared to $6 \%$ of the placebo treatment group), the discontinuation rate was comparable to that observed in previous studies with other selective SRIs (including fluvoxamine IR studies). Of note, there was no significant weight gain with fluvoxamine CR. Finally, as is true for other selective SRIs, the therapeutic index (ratio of lethal to therapeutic dose) of fluvoxamine is high and, consequently, the risk of death with intentional overdosage appears to be relatively low. ${ }^{1}$

\section{Conclusions}

The pharmacokinetics of different SRIs, including fluvoxamine IR, and the associated pattern of side effects hinder a rapid dose escalation, a strategy that may be desirable in the treatment of patients with OCD. The CR formulation of fluvoxamine allows a more aggressive dosing strategy at the beginning of the titration phase and results in a pattern of side effects and compliance that is roughly the same of those seen in fluvoxamine IR. Nevertheless, since there is no headto-head study comparing the efficacy of fluvoxamine CR to that of its IR formulation, it is not possible, at this point, to estimate differences in terms of treatment response between the two formulations.

\section{Disclosures}

The authors declare no conflicts of interest.

\section{References}

1. Goodman WK, Ward H, Kablinger A, et al. Fluvoxamine in the treatment of obsessive-compulsive disorder and related conditions. J Clin Psychiatry. 1997;58 Suppl 5:32-49.

2. van Harten J. Overview of the pharmacokinetics of fluvoxamine. Clin Pharmacokinet. 1995;29 Suppl 1:1-9.

3. Dell'Osso B, Allen A, Hollander E. Fluvoxamine: a selective serotonin re-uptake inhibitor for the treatment of obsessive-compulsive disorder. Expert Opin Pharmacother. 2005;6:2727-2740.

4. Bareggi SR, Mundo E, Dell'Osso B, et al. The use of escitalopram beyond major depression: pharmacological aspects, efficacy and tolerability in anxiety disorders. Expert Opin Drug Metab Toxicol. 2007;3:741-753.

5. Fontenelle LF, Nascimento AL, Mendlowicz MV, et al. An update on the pharmacological treatment of obsessive-compulsive disorder. Expert Opin Pharmacother. 2007;8(5):563-583.

6. Leonard HL, Swedo SE, Lenane MC, et al. A double-blind desipramine substitution during long-term clomipramine treatment in children and adolescents with obsessive-compulsive disorder. Arch Gen Psychiatry. 1991;48:922-927.

7. Barr LC, Goodman WK, Anand A, et al. Addition of desipramine to serotonin reuptake inhibitors in treatment-resistant obsessive-compulsive disorder. Am J Psychiatry. 1997;154:1293-1295.

8. Goodman WK, Price LH, Delgado PL, et al. Specificity of serotonin reuptake inhibitors in the treatment of obsessive-compulsive disorder. Comparison of fluvoxamine and desipramine. Arch Gen Psychiatry. 1990;47:577-585.
9. Mavissakalian M, Turner SM, Michelson L, et al. Tricyclic antidepressants in obsessive-compulsive disorder: antiobsessionals or antidepressant agents? II. Am J Psychiatry. 1985;142:572-576.

10. Ackerman DL, Greenland S. Multivariate meta-analysis of controlled drug studies for obsessive-compulsive disorder. J Clin Psychopharmacol. 2002;22:309-317.

11. Piccinelli M, Pini S, Bellantuono C, et al. Efficacy of drug treatment in obsessive-compulsive disorder. A meta-analytic review. $\mathrm{Br} J$ Psychiatry. 1995;166:424-443.

12. El Mansari M, Blier P. Mechanisms of action of current and potential pharmacotherapies of obsessive-compulsive disorder. Prog Neuropsychopharmacol Biol Psychiatry. 2006;30:362-373.

13. Moresco RM, Colombo C, Fazio F, et al. Effects of fluvoxamine treatment on the in vivo binding of [F-18]FESP in drug naive depressed patients: a PET study. Neuroimage. 2000;12:452-465.

14. Suhara T, Takano A, Sudo Y, et al. High levels of serotonin transporter occupancy with low-dose clomipramine in comparative occupancy study with fluvoxamine using positron emission tomography. Arch Gen Psychiatry. 2003;60:386-391.

15. Takano A, Suhara T, Ichimiya T. Time course of in vivo 5-HTT transporter occupancy by fluvoxamine. J Clin Psychopharmacol. Apr; 2006;26(2):188-191.

16. Takahashi H, Yahata N, Koeda M. Effects of dopaminergic and serotonergic manipulation on emotional processing: a pharmacological fMRI study. Neuroimage. 2005;27:991-1001.

17. Denys D, Zohar J, Westenberg HG. The role of dopamine in obsessivecompulsive disorder: preclinical and clinical evidence. J Clin Psychiatry. 2004;65 Suppl 14:11-17.

18. Moresco RM, Pietra L, Henin M, et al. Fluvoxamine treatment and D2 receptors: a pet study on OCD drug-naïve patients. Neuropsychopharmacology. 2007;32:197-205.

19. Kim CH, Cheon KA, Koo MS, et al. Dopamine transporter density in the basal ganglia in obsessive-compulsive disorder, measured with [123I]IPT SPECT before and after treatment with serotonin reuptake inhibitors. Neuropsychobiology. 2007;55:156-62.

20. Hashimoto K, Ishiwata K. Sigma receptor ligands: possible application as therapeutic drugs and as radiopharmaceuticals. Curr Pharm Des. 2006;12: 3857-3876.

21. Stahl SM. The sigma enigma: can sigma receptors provide a novel target for disorders of mood and cognition. J Clin Psychiatry, 2008;69:1673-1674.

22. Narita $\mathrm{N}$, Hashimoto $\mathrm{K}$, Tomitaka $\mathrm{S}$, et al. Interactions of selective serotonin reuptake inhibitors with subtypes of sigma receptors in rat brain. Eur J Pharmacol. 1996;307:117-119.

23. Ishikawa $M$, Ishiwata $K$, Ishii $K$, et al. High occupancy of sigma-1 receptors in the human brain after single oral administration of fluvoxamine: a positron emission tomography study using [11C]SA4503. Biol Psychiatry. 2007;62:878-883.

24. Egashira N, Harada S, Okuno R, et al. Involvement of the sigma1 receptor in inhibiting activity of fluvoxamine on marble-burying behavior: comparison with paroxetine. Eur J Pharmacol. 2007;563:149-154.

25. Korff S, Harvey BH. Animal models of obsessive-compulsive disorder: rationale to understanding psychobiology and pharmacology. Psychiatr Clin North Am. 2006;29: 371-390.

26. DeVane CL, Gill HS. Clinical pharmacokinetics of fluvoxamine: applications to dosage regimen design. J Clin Psychiatry. 1997;58 Suppl 5: $7-14$.

27. Perucca E, Gatti G, Spina E. Clinical pharmacokinetics of fluvoxamine. Clin Pharmacokinet. 1994;27:175-190.

28. Luvox CR. 2008. Prescribing Information. Palo Alto: Jazz Pharmaceuticals, Inc.

29. Strauss WL, Layton ME, Hayes CE, et al. 19F magnetic resonance spectroscopy investigation in vivo of acute and steady-state brain fluvoxamine levels in obsessive-compulsive disorder. Am J Psychiatry. 1997; $154: 516-522$.

30. Claassen V. 1983. Review of the animal pharmacology and pharmacokinetics of fluvoxamine. Br J Clin Pharmacol. 15 Suppl $3: 349$ S-355S. 
31. Strauss WL, Layton ME, Dager SR. Brain elimination half-life of fluvoxamine measured by $19 \mathrm{~F}$ magnetic resonance spectroscopy. Am J Psychiatry. 1998;155:380-384.

32. Stahl SM. 2005. Essential psychopharmacology: the prescriber's guide. New York: Cambridge University Press.

33. Spina E, Santoro V, D'Arrigo C. Clinically relevant pharmacokinetic drug interactions with second-generation antidepressants: an update. Clin Ther. 2008;30:1206-1227.

34. Irons J. Fluvoxamine in the treatment of anxiety disorders. Neuropsychiatr Dis Treat. 2005;1:289-299.

35. Perse TL, Greist JH, Jefferson JW, et al. Fluvoxamine treatment of obsessive-compulsive disorder. Am J Psychiatry. 1987;144: $1543-1548$.

36. Jenike MA, Hyman S, Baer L, et al. A controlled trial of fluvoxamine in obsessive-compulsive disorder: implications for a serotonergic theory. Am J Psychiatry. 1990;147:1209-1215.

37. Greist JH, Jenike MA, Robinson D, et al. Efficacy of fluvoxamine in obsessive-compulsive disorder: results of a multicentre, double-blind, placebo-controlled trial. Eur J Clin Res. 1995;7:195-204.

38. Goodman WK, Kozak MJ, Liebowitz M, et al. Treatment of obsessivecompulsive disorder with fluvoxamine: a multicentre, double-blind, placebo-controlled trial. Int Clin Psychopharmacol. 1996;11: $21-29$.

39. Cottraux J, Mollard E, Bouvard M, et al. Exposure therapy, fluvoxamine, or combination treatment in obsessive-compulsive disorder: one-year followup. Psychiatry Res. 1993;49:63-75.

40. Hohagen F, Winkelmann G, Rasche-Rüchle H, et al. Combination of behaviour therapy with fluvoxamine in comparison with behaviour therapy and placebo. Results of a multicentre study. Br J Psychiatry. 1998;35 Suppl:71-78.

41. Freeman CP, Trimble MR, Deakin JF, et al. Fluvoxamine versus clomipramine in the treatment of obsessive compulsive disorder: a multicenter, randomized, double-blind, parallel group comparison. J Clin Psychiatry. 1994;55:301-305.

42. Koran LM, McElroy SL, Davidson JR, et al. Fluvoxamine versus clomipramine for obsessive-compulsive disorder: a double-blind comparison. J Clin Psychopharmacol. 1996;16:121-129.

43. Milanfranchi A, Ravagli S, Lensi P, et al. A double-blind study of fluvoxamine and clomipramine in the treatment of obsessivecompulsive disorder. Int Clin Psychopharmacol. 1997;12:131-136.

44. Mundo E, Maina G, Uslenghi C. Multicentre, double-blind, comparison of fluvoxamine and clomipramine in the treatment of obsessivecompulsive disorder. Int Clin Psychopharmacol. 2000;15:69-76.

45. Mundo E, Rouillon F, Figuera ML, et al. Fluvoxamine in obsessivecompulsive disorder: similar efficacy but superior tolerability in comparison with clomipramine. Hum Psychopharmacol. 2001;16: $461-468$.

46. Stein DJ, Spadaccini E, Hollander E. Meta-analysis of pharmacotherapy trials for obsessive-compulsive disorder. Int Clin Psychopharmacol. 1995;10:11-18.
47. Ravizza L, Barzega G, Bellino S, et al. Drug treatment of obsessive-compulsive disorder (OCD): long-term trial with clomipramine and selective serotonin reuptake inhibitors (SSRI). Psychopharmacol Bull. 1996;32:167-173.

48. Mundo E, Bareggi SR, Pirola R, et al. Long-term pharmacotherapy of obsessive-compulsive disorder: a double-blind controlled study. J Clin Psychopharmacol. 1997;17:4-10.

49. Rauch SL, Shin LM, Dougherty DD, et al. Predictors of fluvoxamine response in contamination-related obsessive compulsive disorder: a PET symptom provocation study. Neuropsychopharmacology. 2002;27:782-791.

50. Ho Pian KL, van Megen HJ, Ramsey NF, et al. Decreased thalamic blood flow in obsessive-compulsive disorder patients responding to fluvoxamine. Psychiatry Res. 2005;138:89-97.

51. O'Connor K, Todorov C, Robillard S, et al. Cognitive-behaviour therapy and medication in the treatment of obsessive-compulsive disorder: a controlled study. Can J Psychiatry. 1999;44:64-71.

52. Kordon A, Kahl KG, Broocks A, et al. Clinical outcome in patients with obsessive-compulsive disorder after discontinuation of SRI treatment: results from a two-year follow-up. Eur Arch Psychiatry Clin Neurosci. 2005;255:48-50.

53. Hollander E, Koran LM, Goodman WK, et al. A double-blind, placebocontrolled study of the efficacy and safety of controlled-release fluvoxamine in patients with obsessive-compulsive disorder. JClin Psychiatry. 2003;64:640-647

54. Bogetto F, Albert U, Maina G. Sertraline treatment of obsessivecompulsive disorder: efficacy and tolerability of a rapid titration regimen. Eur Neuropsychopharmacol. 12:181-186.

55. DeVane CL. Immediate-release versus controlled-release formulations: pharmacokinetics of newer antidepressants in relation to nausea. J Clin Psychiatry. 2003;64 Suppl 18:14-19.

56. Tollefson GD, Rampey AH Jr, Potvin JH, et al. A multicenter investigation of fixed-dose fluoxetine in the treatment of obsessive-compulsive disorder. Arch Gen Psychiatry. 1994;51:559-567.

57. Zohar J, Judge R. Paroxetine versus clomipramine in the treatment of obsessive-compulsive disorder. OCD Paroxetine Study Investigators. Br J Psychiatry. 1996;169:468-474.

58. Greist J, Chouinard G, DuBoff E, et al. Double-blind parallel comparison of three dosages of sertraline and placebo in outpatients with obsessivecompulsive disorder. Arch Gen Psychiatry. 1995;52: 289-295.

59. Koran LM, Pallanti S, Paiva RS, et al. Pulse loading versus gradual dosing of intravenous clomipramine in obsessive-compulsive disorder. Eur Neuropsychopharmacol. 1998;8:121-126.

60. Westenberg HG, Stein DJ, Yang H, et al. A double-blind placebo-controlled study of controlled release fluvoxamine for the treatment of generalized social anxiety disorder. J Clin Psychopharmacol. 2004;24:49-55.

61. Luvox. 2004. Prescribing Information. Palo Alto: Jazz Pharmaceuticals, Inc.

62. Davidson J, Yaryura-Tobias J, DuPont R, et al. Fluvoxamine-controlled release formulation for the treatment of generalized social anxiety disorder. J Clin Psychopharmacol. 2004;24:118-125.
Neuropsychiatric Disease and Treatment

\section{Publish your work in this journal}

Neuropsychiatric Disease and Treatment is an international, peerreviewed journal of clinical therapeutics and pharmacology focusing on concise rapid reporting of clinical or pre-clinical studies on a range of neuropsychiatric and neurological disorders. This journal is indexed on PubMed Central, the 'PsycINFO' database and CAS, and is the official

\section{Dovepress}

journal of The International Neuropsychiatric Association (INA). The manuscript management system is completely online and includes a very quick and fair peer-review system, which is all easy to use. Visit http://www.dovepress.com/testimonials.php to read real quotes from published authors. 